\title{
Qualidade de Vida no Trabalho no setor hoteleiro da cidade de Foz do lguaçu
}

\author{
Juliane Louveira Graduada em Administração. Centro Universitário Dinâmica das Cataratas (UDC) Brasil - ju_lovera@hotmail.com \\ Regiane Brustolin Graduada em Administração. Centro Universitário Dinâmica das Cataratas (UDC) Brasil - regiane_brustolin@hotmail.com \\ Giuliano Derrosso Doutorando em Sociedade, Cultura e Fronteiras (UNIOESTE). Centro Universitário Dinâmica das Cataratas (UDC) Brasil - \\ gderrosso@yahoo.com.br
}

\section{RESUMO}

Este trabalho tem por objetivo investigar como está a qualidade de vida no trabalho dentro do ramo da hotelaria na cidade de Foz do Iguaçu, PR. A cidade de Foz do Iguaçu, por estar localizada em uma região de tríplice fronteira, tem sua economia baseada e dependente do Turismo. Por esse motivo esse trabalho justifica-se, pois são esses hotéis que são responsáveis pela satisfação e a imagem que o turista leva da cidade. Foi realizada pesquisa quantitativa onde a técnica de coleta de dados foi questionário para hotéis de categorias Superior e Luxo, segundo a pesquisa da prefeitura Municipal, contabilizando 45 estabelecimentos pesquisados. Como resultados, pode-se observar que os hotéis implementam ações de Qualidade de Vida no Trabalho, mas, em sua maioria, implementam o que é obrigatório por lei, ou que não envolva investimentos financeiros. O trabalho foi baseado na teoria de Walton de QVT, sendo analisado quais fatores estabelecidos na teoria são colocados em prática pelas redes hoteleiras. Na análise realizada, o fator de Integração Social na Empresa foi aquele identificado como os hotéis que mais implementam ações de QVT, assim como o fator Relevância Social da Vida no Trabalho foi o identificado com menos ações implementadas pelos hotéis pesquisados. Nesse setor, há muito a ser melhorado, várias ações de Qualidade de Vida no Trabalho que já deveriam estar implementadas, não foram efetivadas, faltando consciência de que um colaborador satisfeito em seu local de trabalho realiza seu trabalho de forma satisfatória.

Palavras-chave: Qualidade de Vida no Trabalho. Recursos humanos. Satisfação dos colaboradores.

\section{Quality of life at work in the hospitality sector in the city of Foz do lguaçu}

\begin{abstract}
This research aims to investigate the quality of life in the work place in the hospitality industry in the city of Foz do Iguaçu. Because it is located in a region of a triple border, the city of Foz do Iguaçu has its economy based and dependent on Tourism. For this reason this work is justified, as it is these hotels that are responsible for the satisfaction and the image that the tourist takes of the city. A quantitative survey was carried out where the data collection technique was a questionnaire for hotels of Superior and Luxury categories, according to the City Hall survey, accounting for 45 researched establishments. As a result, it can be observed that hotels implement Quality of Life actions at work, but, for the most part, they implement what is required by law, or actions that do not involve financial investments. The work was based on Walton's theory of QVT, analyzing what factors established in the theory are put into practice by hotel chains. In the analysis carried out, the factor of Social Integration in the Company was the one identified as the most implemented QVT actions. The Social Relevance of Work Life factor was identified as the item with fewer actions implemented by the hotels surveyed. In this sector there is a lot to be improved, several quality of life actions at work that should already have been adopted have not been implemented yet. This shows lack of awarenesss that an employee satisfied at his place of work, performs his work satisfactorily.
\end{abstract}

Keywords: Quality of Life at Work. Human Resources. Employee Satisfaction. 


\section{INTRODUÇÃO}

Quando uma cidade tem como principal economia o turismo, a gestão hoteleira deve ser de qualidade, pois essas cidades recebem um grande número de visitantes, onde os prestadores de serviço acabam tendo que lidar com as particularidades relacionadas às expectativas de cada cliente.

A cidade de Foz do Iguaçu tem como maior parte da economia o Turismo, no qual, segundo uma pesquisa realizada pelo Parque Nacional do Iguaçu, nos meses de janeiro a agosto de 2014, o parque recebeu cerca de 985.306 visitantes, último dado disponível em relação à quantidade de visitantes que a cidade recebeu.

Segundo a Prefeitura Municipal de Foz do Iguaçu (2015), no ano de 2014, a cidade teve 176 opções de meio de hospedagem, totalizando entre esses, 27.588 o número de leitos que essa cidade disponibilizou nesse mesmo ano.

É nesse ponto que a gestão da hotelaria se torna importante. Com esse número de visitantes, há a necessidade de uma expectativa boa do local visitado por parte do turista e por isso o gestor deve saber lidar com os desafios de planejamento e gerenciamento, para oferecer qualidade na prestação do serviço nesse setor. Isso comprova quando um turista se sente acolhido na cidade visitada, e passa por uma experiência agradável, em seu ponto de vista, acaba retornando à cidade.

Para atender essa demanda com excelência, as empresas do ramo de hotelaria devem ter colaboradores que estejam de acordo com a missão da empresa, objetivando assim os resultados que elas almejam alcançar que é a satisfação dos clientes.

O setor de recursos humanos da empresa de hotelaria deve estar devidamente treinado para escolher os melhores colaboradores para trabalhar nesse ambiente, realizando assim o processo de atrair, treinar e reter os colaboradores excepcionais para cada cargo.

Além da escolha por colaboradores que atenda o que a empresa deseja, a mesma deve investir em meios para mantê-los no ambiente de trabalho, pois as pressões por resultados aumentam, consequentemente fazendo com que acarrete efeitos negativos para o colaborador, sendo eles: cansaço, stress, depressão, baixa estima, doenças, acidentes de trabalho, e tudo isso pode resultar no afastamento desse colaborador.

As empresas, que investem em qualidade de vida no local de trabalho para os colaboradores, tendem a ter resultados satisfatórios, pois os mesmos percebem que suas necessidades estão sendo atendidas, resultando assim em um maior comprometimento, valorização do local de trabalho, responsabilidades e motivações, pois um colaborador que esteja motivado aumenta a produtividade, tornando-se assim um benefício para a empresa.

É importante ressaltar que a Qualidade de Vida no Trabalho é o quão a pessoa está satisfeita com sua carreira, satisfeita no seu local de trabalho, e quando suas necessidades estão sendo devidamente atendidas. Para uma pessoa, sua satisfação consiste em alcançar determinado cargo em uma empresa, diferentemente para outro que almeja outra necessidade e que julgue tal como importante.

A cidade de Foz do lguaçu vem recebendo vários turistas, não só pelos seus pontos turísticos, mas também pela estrutura que comporta grandes eventos em níveis nacionais e internacionais.

A grande referência da cidade de Foz do Iguaçu continua sendo as Cataratas do Iguaçu, e também a Usina Hidrelétrica de Itaipu, e por esse motivo a necessidade de colaboradores aptos a atender esse público que consomem estadia, gastronomia, cultura e lazer.

O grande desafio dos empresários da cidade de Foz do lguaçu é atender esse consumo com qualidade e entender que investir no colaborador é a chave para a excelência, pois um colaborador satisfeito resulta em um cliente satisfeito.

Geralmente, a área de recursos humanos, treina e realiza a capacitação dos seus colaboradores para encantar o hóspede do hotel, porém, os recursos humanos devem entender que não apenas deve cativar seus clientes externos, mais também seus clientes internos que são os colaboradores, pois é certo que se os clientes internos não estão felizes no local de trabalho, também não haverá essa troca de qualidade com o cliente externo (CASTELLI, 2003).

E é por esse motivo que a qualidade de vida no setor hoteleiro de Foz do lguaçu deve ser vista com a atenção que merece, porque o colaborador que está motivado com ações e práticas de melhorias no ambiente de trabalho, e sendo reconhecido, vai executar suas funções de forma satisfatória, resultando em um bom atendimento e na percepção final do cliente, e o retorno dele para a cidade.

Diante do exposto questiona-se: Quais ações de Qualidade de Vida no Trabalho são implementadas pelo setor hoteleiro nas categorias Luxo e Superior da cidade de Foz do Iguaçu?

Para responder a essa pergunta, o objetivo geral dessa pesquisa foi analisar como os hotéis estão implementando as ações de Qualidade de Vida no Trabalho no setor hoteleiro da cidade de Foz do lguaçu. 
Para que se concretizasse o resultado foi necessário estabelecer três objetivos específicos: o primeiro foi pesquisar os métodos e ações de Qualidade de Vida no Trabalho existentes na literatura do assunto; o segundo objetivo especifico foi realizar um diagnóstico do setor hoteleiro da cidade de Foz do lguaçu, identificando sua importância para a cidade, e terceiro e último foram identificadas as ações de Qualidade de Vida no Trabalho realizadas pelo setor hoteleiro da cidade de Foz do Iguaçu.

A Qualidade de Vida no Trabalho é vista como um tema atual, pelo fato de as organizações enxugarem cada vez mais seu quadro de funcionários, pressionando os que ali ficam. Dessa forma, a QVT busca diminuir os efeitos negativos do trabalho para que dele não resultem doenças ou prejuízos para a empresa.

E isso é exatamente o que os gestores almejam e estudam, para gerenciar, organizar, direcionar e controlar de forma eficaz todos os desafios do dia a dia.

Ao se tratar de satisfação do colaborador, aplicando corretamente os métodos de Qualidade de Vida no Trabalho, a organização acaba obtendo um diferencial competitivo muito grande, e no caso do setor hoteleiro, imprescindível, visto que os resultados satisfatórios da experiência que o turista busca ao visitar a cidade, está em grande parte no bom atendimento que ele recebe, desde sua chegada, até sua partida. É essa boa lembrança que vai fazer com que ele resolva permanecer mais alguns dias consumindo na cidade, indicar a cidade de Foz do lguaçu para outras pessoas como destino, e também voltar a visitar.

Desse modo, se pode entender o quanto um colaborador satisfeito, bem treinado e adaptado com certa situação, ressalta na colaboração com o setor. E esse é o grande desafio dessa pesquisa, esclarecer as dúvidas do setor hoteleiro, conhecer e saber se existem ações e práticas de Qualidade de Vida no Trabalho que já estão acontecendo, e assim mostrar que essas ações são vistas como um diferencial, que traz resultados positivos tanto para o colaborador, como para as empresas e assim para a área de turismo.

Com isso, o turismo da cidade pode se beneficiar dessa pesquisa, gerando informações úteis e influenciando o crescimento da economia da cidade num todo.

\section{REVISÃO DE LITERATURA}

A revisão de literatura tem como objetivo a busca por teorias que dizem a respeito do estudo que está sendo abordado, podendo ser buscadas em livros, teses, artigo, periódicos, entre outros.

\subsection{Qualidade de Vida no Trabalho}

Nesta seção abordaremos a Qualidade de Vida no Trabalho (QVT), a conceitualização desse assunto, as teorias que envolvem esse contexto, as ações que são consideradas como Qualidade de Vida no Trabalho e entre outros.

Durante muito tempo o trabalho se realizou sob a forma de coleta e de trabalho extrativo. Um pouco mais tarde, surgiu a pesca, a caça e o pastoreio. Até então a preocupação era para a subsistência, ou melhor, a própria sobrevivência. Com a agricultura, passou-se a produzir um excedente do que se poderia consumir, e como consequência, a escravização de pessoas. Com a revolução industrial, no século XVIII, exigia-se um novo modelo de organização do trabalho: a especialização das tarefas e a divisão do trabalho. (ROCHA, 2012, p. 112).

Na década de 1970, Louis Davis foi o responsável pelo termo Qualidade de Vida no Trabalho, pois estava desenvolvendo um plano sobre desenho de cargos. A Qualidade de Vida no Trabalho para Louis era o bem-estar do colaborador e a saúde do mesmo, na realização das tarefas. Hoje em dia não são apenas os aspectos físicos e ambientais que envolvem a Qualidade de Vida no Trabalho, mais também o aspecto psicológico do colaborador no seu local de trabalho (CHIAVENATO, 2004a).

Gil (2001) defende que durante vários anos, quando se falava em qualidade nas empresas, diretamente já se associava à produção. Mas hoje, ao falar-se em Qualidade de Vida no Trabalho, já é vista de outra forma, como qualidade de vida dos colaboradores e por isso eles devem trabalhar mais felizes; para que isso seja possível, os colaboradores devem sentir que estão executando suas tarefas com as habilidades que possuem, e que eles são tratados como pessoas na organização.

A qualidade de vida é a forma de pensar acerca das pessoas, do trabalho e das organizações, onde se sobressaem duas posições: a preocupação com o bem-estar do colaborador, a Qualidade de Vida no Trabalho e a participação do colaborador nas decisões e problemas a serem solucionados na organização (ROCHA, 2012). 
No ambiente de trabalho, a qualidade de vida, saúde e ergonomia associa-se à ética da condição humana. A atitude ética compreende desde identificação, eliminação, neutralização ou controle dos riscos ocupacionais observáveis no ambiente físico, padrões de relações de trabalhos, carga física e mental requerida para cada atividade, implicações políticas e ideológicas, dinâmica de liderança empresarial e do poder formal ou informal, o significado do trabalho em si até o relacionamento e satisfação das pessoas no seu dia a dia. (FRANÇA, 2011, p. 167).

Segundo Marras (2011), as organizações preocupam-se em obter resultados e os alcances de suas metas, exigindo muito de seus colaboradores, fazendo com que isso gere um estresse pela busca excessiva de resultados imposta pelas organizações. As empresas devem conscientizar-se que a massa de trabalhadores busca viver com qualidade e melhor. Os sindicatos reivindicam essa questão desde 1980, a implantação da Qualidade de Vida no Trabalho. E por esse motivo, muitas empresas estão buscando se adequar a isso com treinamentos e políticas para atender essa necessidade.

Para França (2004), atualmente a QVT passa a englobar não apenas o chão de fábrica, onde era o alvo de programas de saúde e de segurança no trabalho, mas também todos os demais departamentos com colaboradores na empresa como a gerência e a alta direção. Historicamente, as questões de Qualidade de Vida no Trabalho envolviam a saúde e a segurança no trabalho, mas vêm abrangendo esse conceito, há uma emergência das habilidades, atitudes e conhecimento, associando-se com legitimidade, experiências, competências gerenciais e integração social.

A qualidade do trabalho quando está elevada faz com que haja respeito e um clima de confiança dentro da organização, com mais responsabilidade. Sabendo que a importância das necessidades de cada colaborador varia, a cultura de cada um deles e de cada organização varia de uma para a outra. Então, a QVT não pode apenas ser determinada com características de cada indivíduo ou de cada situação, mas sim pelo o que cada empresa ou colaborador segue como cultura em seu âmbito (CHIAVENATO, 2004a).

Na visão de Rocha (2012), a Qualidade de Vida no Trabalho não é apenas métodos para manter o colaborador na organização, mas também forma de estudar e aplicar as melhores condições para o ser humano se desenvolver seja mental, emocional ou social.

QVT deve ser considerada como uma gestão dinâmica, porque as pessoas mudam constantemente, dependendo da realidade de cada instituição, no contexto em que se encontram. Além disso, pouco resolve atentar apenas para fatores físicos, pois aspectos sociológicos e psicológicos interferem igualmente na satisfação dos indivíduos em situações de trabalho, sem deixar de considerar os aspectos tecnológicos da organização do próprio trabalho, que, em conjunto, afetam a cultura e interferem no clima organizacional, com reflexos na produtividade e na satisfação dos empregados. (ROCHA, 2012, p. 86).

Acrescentam Motta e Sousa (2008), que a Qualidade de Vida no Trabalho é a busca pela humanização do trabalho, fazendo com que o trabalhador tenha uma boa qualidade de vida, englobando aspectos de motivação pessoal, fatores ergonômicos, fatores ambientais, e satisfação no trabalho gerando assim aspectos que resultam no bem-estar, na segurança e na realização das tarefas propostas pela empresa com excelência.

Em vista disto, a Qualidade de Vida no Trabalho deve apresentar esses aspectos para gerar assim os resultados tanto para o colaborador, quanto para a empresa, pois como sabemos o trabalhador que executa as tarefas com qualidade e bem-estar acaba resultando em qualidade para a empresa, e a realização do proposto para ele com responsabilidade.

Bom Sucesso (2002) apresenta que a Qualidade de Vida no Trabalho está relacionada com a autoestima do colaborador, com o orgulho que ele sente na realização do trabalho, se a renda é favorável com o trabalho desenvolvido, se os horários propostos para o colaborador são sensatos para que assim ele tenha um equilíbrio entre o lazer e o trabalho, se a empresa respeita os direitos de seus colaboradores, se há uma oportunidade de crescimento e carreiras dentro da organização e, por fim, se há uma recompensa justa por parte da empresa pelo serviço desenvolvido pelo colaborador.

Para Bom Sucesso (2002) os colaboradores não buscam em uma empresa apenas salários, mas sim desenvolvimentos, aprendizagens, oportunidades de crescimento, amizades, reconhecimento pelo trabalho desenvolvido. Por sua vez, a empresa deve buscar os colaboradores comprometidos em realizar os objetivos da organização, resultando assim, para o cliente final, serviços e produtos com qualidade.

As ações de Qualidade de Vida no Trabalho têm dois objetivos: um deles é o aumento da produtividade e o desempenho do colaborador, o outro é melhorar a satisfação do mesmo no local de trabalho. Os autores acreditam que esses dois objetivos estejam ligados entre si, pois, melhorando as condições com a satisfação do trabalho, resulta 
na melhora da produtividade, mas isso não significa que a satisfação e a produtividade andam sempre juntas (ROSA, 2006).

\begin{abstract}
Uma empresa boa para se trabalhar certamente implica uma preocupação genuína com a integridade das pessoas. A organização contemporânea não admite um ambiente que ofereça risco de vida ou condições de insalubridade. A integridade do empregado não está reduzida ao aspecto físico, se estende também ao psicológico e social. As pessoas, para se desenvolverem precisam sentir-se valorizadas em relação ao trabalho que executam e seguras quanto a sua importância para a empresa e para as pessoas com as quais convive. (ROCHA, 2012, p. 41).
\end{abstract}

O Quadro 1 traz a visão de diversos autores a respeito do conceito de Qualidade de Vida no Trabalho.

Quadro 1 - Conceitos de Qualidade de Vida no Trabalho

\begin{tabular}{|l|l|}
\hline Referência & Ênfase no conceito de Qualidade de Vida no Trabalho \\
\hline $\begin{array}{l}\text { Hannif, Burgess e } \\
\text { Connell (2008) }\end{array}$ & $\begin{array}{l}\text { Qualidade de Vida no Trabalho é um conceito multidimensional e dinâmico que } \\
\text { busca incorporar todas e quaisquer medidas subjetivas e objetivas relacionadas à } \\
\text { qualidade do emprego. }\end{array}$ \\
\hline $\begin{array}{l}\text { Korunka, Hoonakker } \\
\text { e Carayon (2008) }\end{array}$ & $\begin{array}{l}\text { Qualidade de Vida no Trabalho pode ser representada pelas dimensões } \\
\text { satisfação no trabalho, envolvimento organizacional e desgaste emocional. }\end{array}$ \\
\hline $\begin{array}{l}\text { Cheung e Tang } \\
(2009)\end{array}$ & $\begin{array}{l}\text { Qualidade de Vida no Trabalho significa satisfazer as diversas necessidades dos } \\
\text { empregados. }\end{array}$ \\
\hline Kompier et al. (2009) & $\begin{array}{l}\text { Qualidade de Vida no Trabalho é representada pelas dimensões: carga de horas } \\
\text { de trabalho, características psicossociais e carga física do trabalho. }\end{array}$ \\
\hline $\begin{array}{l}\text { Otto, Glasser e } \\
\text { Dalbert (2009) }\end{array}$ & Qualidade de Vida no Trabalho significa estar satisfeito com o trabalho. \\
\hline $\begin{array}{l}\text { Limongi-França } \\
(2009)\end{array}$ & $\begin{array}{l}\text { A Qualidade de Vida no Trabalho é um conjunto individual de escolhas de bem- } \\
\text { estar que gera resultados positivos ao ser humano, como por exemplo, a } \\
\text { autoestima positiva, hábitos saudáveis ou a prontidão para o desempenho do } \\
\text { trabalho. }\end{array}$ \\
\hline $\begin{array}{l}\text { Koonmee et al. } \\
\text { (2010) }\end{array}$ & $\begin{array}{l}\text { Qualidade de Vida no Trabalho significa satisfazer as diversas necessidades dos } \\
\text { empregados. }\end{array}$ \\
\hline
\end{tabular}
Fonte: Adaptado de Chiavenato (2004b)

O Quadro 2 traz os critérios de Qualidade de Vida no Trabalho e o foco para cada um. O organizacional como o nome já diz, está voltado para a empresa, onde estão os treinamentos que a empresa disponibiliza para o colaborador, é a própria imagem da empresa diante da sociedade, as rotinas, os processos que são desenvolvidos e outros. O critério biológico é o que está envolvido na saúde e segurança do colaborador, como controle de riscos ergonômicos, ginástica laboral, CIPA. O sistema critério psicológico está relacionado como é realizada a avaliação de desempenho desse colaborador, o clima organizacional dentro da empresa, como está a vida pessoal do colaborador, pois envolve a empresa onde trabalha, como a empresa disponibiliza possibilidade de carreira dentro da organização. Por último, o critério social envolve financiamentos de cursos para os colaboradores se especializarem, convênios comerciais, tempo livre para o colaborador descansar e outros.

Quadro 2 - Indicadores de QVT.

\begin{tabular}{|l|l|}
\hline \multicolumn{1}{|c|}{ Critérios } & \multicolumn{1}{c|}{ Foco } \\
\hline Organizacional & $\begin{array}{l}\text { Imagem, Treinamento e Desenvolvimento, Processos e Tecnologias, Comitês de } \\
\text { Decisão, Ausência de Burocracia, Rotinas de pessoal. }\end{array}$ \\
\hline Biológico & Controle de riscos ergonômicos, Ginástica Laboral, Refeitório, ClPA. \\
\hline Psicológico & $\begin{array}{l}\text { Recrutamento e Seleção, Avaliação de desempenho, Clima organizacional, Carreira, } \\
\text { Salário, Vida pessoal. }\end{array}$ \\
\hline Social & $\begin{array}{l}\text { Convênios Comerciais, Tempo livre, Cesta básica, Previdência Privada, } \\
\text { Financiamento de Cursos. }\end{array}$ \\
\hline
\end{tabular}

$$
\text { Fonte: França (2011, p. 36). }
$$

Segundo França (2011), as competências de QVT podem ser encontradas nas áreas de: Saúde; Gestão de pessoas; Ergonomia; Benefícios; Sistemas de gestão de qualidades, e outros.

\title{
2.1.1 Teorias de Qualidade de Vida no Trabalho.
}


A QVT apresenta vários modelos que foram desenvolvidos no decorrer dos anos, nesse estudo iremos abordar as que são defendidas pelos autores Nadler e Lawler, Hackman e Oldhan e o autor Walton.

Para Nadler e Lawler (1983 apud CHIAVENATO, 2004a), se a empresa implementar os aspectos que estão sendo mostrados no quadro abaixo, ocorrerá consequentemente a melhoria na Qualidade de Vida no Trabalho de seus colaboradores. O modelo de Nadler e Lawler valoriza o quão as tarefas realizadas pelos colaboradores significam para eles, e o modo como as expectativas são alcançadas, e assim melhoradas em relação ao ambiente de trabalho (Quadro 3).

Quadro 3 - Modelo de QVT de Nadler e Lawler.

\begin{tabular}{|l|l|}
\hline & MODELO DE QVT DE NADLER E LAWLER \\
\hline 1 & Participação dos funcionários nas decisões. \\
\hline 2 & $\begin{array}{l}\text { Reestruturação do trabalho através do enriquecimento de tarefas e de grupos } \\
\text { autônomos de trabalho. }\end{array}$ \\
\hline 3 & Inovação no sistema de recompensas para influenciar o clima organizacional. \\
\hline 4 & Melhoria no ambiente de trabalho quanto a condições físicas e psicológicas, horário de trabalho etc. \\
\hline
\end{tabular}

No modelo de Nadler e Lawler a, participação do colaborador nas decisões da empresa é uma forma de que haja um aumento na Qualidade de Vida no Trabalho, como também um melhoramento das tarefas a serem desenvolvidas pelos mesmos, um sistema de recompensa melhorado, onde haja uma motivação influenciando o colaborador, também a melhoria física no ambiente de trabalho, preocupando-se com a saúde e a segurança do colaborador.

No modelo de Hackman e Oldhan representado no Quadro 4, os autores acreditam que as dimensões do cargo podem apresentar os resultados pessoais ou de trabalho, pois busca a ligação entre as tarefas do colaborador e os estados psicológicos do mesmo (CHIAVENATO, 2004a).

Quadro 4 - Modelo de QVT de Hackman e Oldhan

\begin{tabular}{|l|}
\hline MODELO DE QVT DE HACKMAN E OLDHAN \\
\hline $\begin{array}{l}\text { Variedade de habilidades: o cargo requer várias e diferentes habilidades, } \\
\text { conhecimentos e competências da pessoa. }\end{array}$ \\
\hline $\begin{array}{l}\text { Identidade de tarefa: o trabalho dever ser realizado do início ao fim para que a pessoa } \\
\text { possa perceber que produz um resultado palpável. }\end{array}$ \\
\hline $\begin{array}{l}\text { Significado de tarefa: a pessoa deve ter uma clara percepção de como o seu trabalho } \\
\text { produz consequências e impactos sobre o trabalho das outras. }\end{array}$ \\
\hline $\begin{array}{l}\text { Autonomia: a pessoa deve ter responsabilidade pessoal para planejar e executar as } \\
\text { tarefas, autonomia própria e independência para desempenhar. }\end{array}$ \\
\hline $\begin{array}{l}\text { Retroação do próprio trabalho: a tarefa deve proporcionar informação de retorno à } \\
\text { pessoa para que ela própria possa autoavaliar seu desempenho. }\end{array}$ \\
\hline $\begin{array}{l}\text { Retroação extrínseca: deve haver o retorno proporcionado pelos superiores } \\
\text { hierárquicos ou clientes a respeito do desempenho de tarefas. }\end{array}$ \\
\hline $\begin{array}{l}\text { Inter-relacionamento: a tarefa deve possibilitar contato interpessoal do ocupante com } \\
\text { outras pessoas ou com clientes internos e externos. }\end{array}$ \\
\hline
\end{tabular}

Fonte: Chiavenato (2004a, p. 96).

Para Walton, alguns fatores são primordiais na Qualidade de Vida no Trabalho onde são mostrados os fatores e as dimensões desse modelo defendido pelo autor.

Nessa abordagem, não estão apenas os aspectos internos, mas também os aspectos externos da organização. O interesse é pelas tarefas que irão ser desenvolvidas na empresa, pelo relacionamento e logo, pelas consequências do colaborador fora dela.

Outro modelo de Qualidade de Vida no Trabalho é o modelo de Walton, onde apresentam oito fatores básicos segundo Chiavenato (2004b):

1) Compensação justa e adequada: é a remuneração pelo trabalho que o colaborador realiza, correspondendo a salário, benefício e outros, devendo haver também uma equidade tanto interna quanto externa na organização, para que os colaboradores de mesma função recebam o mesmo valor de remuneração, não deve haver distinção. 
2) Condições de segurança e saúde no trabalho: a jornada de trabalho do colaborador deve promover segurança sem prejudicar a saúde do colaborador, o ambiente físico deve ser saudável e adequado para o mesmo.

3) Utilização e desenvolvimento de capacidades: quando um colaborador tem alguma habilidade e conhecimento, a organização aproveita disso para promover oportunidades para esse colaborador, nesse fator também é realizado o feedbackao colaborador sobre seu desempenho e a organização deve informar as atividades que os mesmos devem realizar na execução de seu trabalho.

4) Oportunidade de crescimento e segurança: a organização: no sentido de a organização oferecer conhecimento na área que o colaborador está atuando, como também treinar e desenvolver o trabalhador, oferecer uma estabilidade de emprego.

5) Integração social na empresa: é o que envolve a intolerância ao preconceito e eliminação de problemas que ocorrem de hierarquia.

6) Garantias constitucionais: São as normas e regras da empresa como também os diretos e deveres do colaborador dentro da organização.

7) Trabalho e espaço total de vida: a organização deve proporcionar momentos de lazer para o colaborador, pois o trabalho não deve retirar toda a energia dele, deve haver um tempo para sua vida familiar e atividades comunitárias.

8) Relevância social da vida no trabalho: ao trabalhar em uma organização o colaborador deve sentir orgulho por isso, ela deve ter uma imagem respeitada diante da sociedade.

O quadro 5 mostra esses oito fatores de Qualidade de Vida no Trabalho segundo o modelo de Walton como também suas dimensões.

Quadro 5 - Modelo de QVT de Walton.

\begin{tabular}{|c|c|}
\hline \multicolumn{2}{|c|}{ O MODELO DE QVT DE WALTON } \\
\hline FATORES DE QVT & DIMENSÕES \\
\hline 1) Compensação justa e adequada & $\begin{array}{l}\text { 1. Renda (salário) adequada ao trabalho } \\
\text { 2. Equidade interna } \\
\text { 3. Equidade externa }\end{array}$ \\
\hline $\begin{array}{l}\text { 2) Condições de segurança e saúde no } \\
\text { trabalho }\end{array}$ & $\begin{array}{l}\text { 4. Jornada de trabalho } \\
\text { 5. Ambiente físico (seguro e saudável) }\end{array}$ \\
\hline $\begin{array}{l}\text { 3) Utilização e desenvolvimento de } \\
\text { capacidades }\end{array}$ & $\begin{array}{l}\text { 6. Autonomia } \\
\text { 7. Significado da tarefa } \\
\text { 8. Identidade da tarefa } \\
\text { 9. Variedade de habilidades } \\
\text { 10. Retroação e Retroalimentação }\end{array}$ \\
\hline $\begin{array}{l}\text { 4) Oportunidade de crescimento e } \\
\text { segurança }\end{array}$ & $\begin{array}{l}\text { 11. Possibilidade de carreira } \\
\text { 12. Crescimento profissional } \\
\text { 13. Segurança do trabalho }\end{array}$ \\
\hline 5) Integração social na organização & $\begin{array}{l}\text { 14. Igualdade de oportunidades } \\
\text { 15. Relacionamentos interpessoais e grupais } \\
\text { 16. Senso comunitário }\end{array}$ \\
\hline 6) Trabalho e espaço total de vida & 17. Papel balanceado do trabalho na vida pessoal \\
\hline $\begin{array}{l}\text { 7) Relevância social da vida no } \\
\text { trabalho }\end{array}$ & $\begin{array}{l}\text { 18. Imagem da empresa } \\
\text { 19. Responsabilidade social pelos produtos/serviços } \\
\text { 20. Responsabilidade social pelos empregados }\end{array}$ \\
\hline
\end{tabular}

Fonte: Chiavenato (2004a, p. 102)

O colaborador deve participar das decisões dentro da organização, pois isso é um dos fatores que irá lhe causar uma satisfação. Os pressupostos desses autores podem ser observados no Quadro 6.

Quadro 6 - Autores e pressupostos de avaliação QVT

\begin{tabular}{|l|l|}
\hline Autor & Pressuposto \\
\hline Westley (1979) & $\begin{array}{l}\text { Classifica e analisa a natureza de quatro problemas que afetam diretamente a } \\
\text { Qualidade de Vida no Trabalho: econômico, político, psicológico e } \\
\text { sociológico. Os mesmos aparecem sob a forma de injustiça, insegurança, } \\
\text { alienação e anomia ou ausência de leis e regulamentos, tendo como } \\
\text { indicadores de insatisfação, greves, desinteresse, absenteísmo e falta de } \\
\text { sentido no trabalho. }\end{array}$ \\
\hline
\end{tabular}




\begin{tabular}{|l|l|}
\hline Werther e Davis (1983) & $\begin{array}{l}\text { Pauta-se um projeto de cargo que considera fatores ambientais (sociais, } \\
\text { tecnológicos, culturais, econômicos e governamentais), organizacionais } \\
\text { (propósitos, objetivos, organização, departamentos e cargos) e } \\
\text { comportamentais (necessidades de recursos humanos, motivação, } \\
\text { satisfação). }\end{array}$ \\
\hline Huse e Cummings (1985) & $\begin{array}{l}\text { Concebem a QVT como uma forma de pensamento que envolve pessoas, } \\
\text { trabalho e organização. A participação dos trabalhadores nas decisões e } \\
\text { problemas do trabalho é um aspecto central que objetiva o bem-estar do } \\
\text { trabalhador e a eficácia organizacional. O modelo de aferição do nível de QVT } \\
\text { baseia-se na participação dos trabalhadores, nos processos decisórios em } \\
\text { diversos níveis da organização. Além disso, envolve projeto de cargo, } \\
\text { inovação no sistema de recompensa e melhoria no ambiente de trabalho. }\end{array}$ \\
\hline
\end{tabular}

Fonte: Adaptado de Pereira e Peçanha (2005, p. 5 apud GORZONI, 2010, p. 9).

\section{METODOLOGIA DA PESQUISA}

"A metodologia é as regras estabelecidas para o método científico, por exemplo, a necessidade de observar, a necessidade de formular hipóteses, a elaboração de instrumentos etc". (RICHARDSON, 1999, p. 22).

Nesta etapa será abordada a metodologia do estudo, como a tipologia da pesquisa, os métodos que foram utilizados, a técnica de coleta de dados que foi aplicada na pesquisa, a população-alvo e a amostragem e a técnica de análise de dados para melhor compreensão do estudo.

A pesquisa cientifica se aplica nesse estudo, pois o objetivo foi buscar saber quais ações de Qualidade de Vida no Trabalho que as empresas de Foz do Iguaçu implementam, e isso será realizado por meio de pesquisa no setor de hotelaria, analisar esse ambiente, e assim ter as respostas das perguntas questionadas como problema no estudo respondidas cientificamente.

O método de pesquisa, utilizado nesse trabalho, é a pesquisa quantitativa. Richardson, (1999, p. 70) define que "o método quantitativo representa, em princípio, a intenção de garantir a precisão dos resultados, evitar distorções de análise e interpretação possibilitando, consequentemente, uma margem de segurança quanto às inferências".

Diante dessa teoria apresentada, podemos identificar que a pesquisa deverá atender apenas o método quantitativo, pois ele traz a precisão dos resultados por meio de dados estatísticos, e é o que será realizado nesse estudo, pois haverá a aplicação de um questionário nas empresas de hotelaria de Foz do Iguaçu, e o resultado dessa aplicabilidade é os números que irão ser analisados para responder ao problema de pesquisa proposto pelo estudo.

As técnicas de coleta de dados que foram utilizadas nesse estudo são as: pesquisas bibliográficas e o questionário, que no próximo tópico serão encontrados as definições e aplicações de cada um deles. O questionário foi aplicado nos hotéis da cidade de Foz do Iguaçu, onde houve uma limitação de que fosse aplicado nas empresas com categorias de diárias com o valor a partir de $\mathrm{R} \$ 161,00$ do ano de 2014, considerados segundo a Prefeitura Municipal de Foz do Iguaçu como sendo das categorias Luxo e Superior. Por isso, o questionário foi aplicado com 45 estabelecimentos, onde o responsável pelo hotel respondia à pesquisa que possuía 54 perguntas. Para a construção desse questionário, foi utilizado o modelo de Qualidade de Vida no Trabalho de Walton, possuindo 8 fatores, e em cada fator havia de 5 a 7 ações de QVT. "Uma população é o total de elementos que compartilham algum conjunto comum de características" (MALHOTRA, 2005, p. 258).

O meio de coleta de dados que está presente nesse estudo é o questionário. "A informação obtida por meio do questionário permite observar as características de um indivíduo ou grupo. Por exemplo: sexo, idade, estado civil, nível de escolaridade, preferências políticas etc." (RICHARDSON, 1999, p. 189).

O objetivo de aplicação desse questionário era para saber se os hotéis da cidade de Foz do Iguaçu enquadrados como Superior e Luxo implementam ações de QVT em seus estabelecimentos para seus colaboradores; o resultado esperado era que todos os 45 estabelecimentos respondessem o questionário e o resultado disso haver um êxito nessa pesquisa, como também, gerar informações para o turismo da cidade. Por isso, a população-alvo desse estudo foram os hotéis de Foz do Iguaçu, com categorias de diárias com o valor a partir de R\$ 161,00 do ano de 2014, totalizando assim, 45 hotéis. Ao calcular a amostra, com um erro amostral de 5\%, um nível de confiança de $95 \%$ e o percentual máximo de 50\%, a amostra necessária para o estudo resulta em 41 hotéis responderam dos 45 definidos nesta pesquisa.

A técnica de análise de dados que está presente nesse estudo é a análise estatística, pois com a aplicação do questionário definido no tópico acima, há a necessidade da análise dos dados obtidos com ele. 
“Na pesquisa de caráter quantitativo, normalmente os dados coletados são submetidos à análise estatística, com a ajuda de computadores (se o número de casos pesquisados ou o número de itens costuma-se utilizar uma planilha para a codificação manual dos dados)" (ROESCH, 1999, p. 149).

\section{ANÁLISE DOS RESULTADOS}

A análise dos resultados tem como objetivo apontar quais são as características que mais se destacaram na aplicação do questionário com a finalidade de responder os objetivos que foram propostos nesta pesquisa, onde as respostas dos questionamentos estão apresentadas em gráficos.

Para a obtenção dos dados, o questionário foi aplicado nos hotéis da cidade de Foz do lguaçu, classificados segundo a pesquisa da Prefeitura Municipal da cidade no ano de 2014 como sendo Superior e Luxo apresentado no capítulo 2 desta pesquisa. A pesquisa foi realizada com 42 hotéis do total de 45 , pois 3 destes se recusaram a participar e responder aos questionários.

Os questionários foram enviados às empresas por meio de e-mail, a partir do dia 15 de março de 2016, onde 3 hotéis responderam, para os restantes 39, foram levados e deixados na empresa os questionários, entre os dias 30 de março até 21 de abril, onde o setor de RH do hotel foi responsável em responder e avisar quando os questionários estivessem prontos para retornar a buscar. Isso ocorreu devido ao fato que os setores de RH estavam em fechamento do mês por isso não poderiam responder naquele momento.

O questionário aplicado nas empresas, apresentava 3 questões abertas, onde a empresa deveria responder com a realidade da mesma, e 51 questões onde a empresa deveria assinalar com $\mathrm{X}$ no que considerava a realidade dela.

A primeira pergunta questionada era em relação à quantidade de colaboradores que existiam na empresa. Como era uma pergunta aberta, foi definido em uma escala que varia de 50 em 50 tornando assim melhor a identificação e a análise dos dados, podendo assim ser observado o resultado dessa pergunta no gráfico 1.

Gráfico 1 - Quantidade de colaboradores na empresa

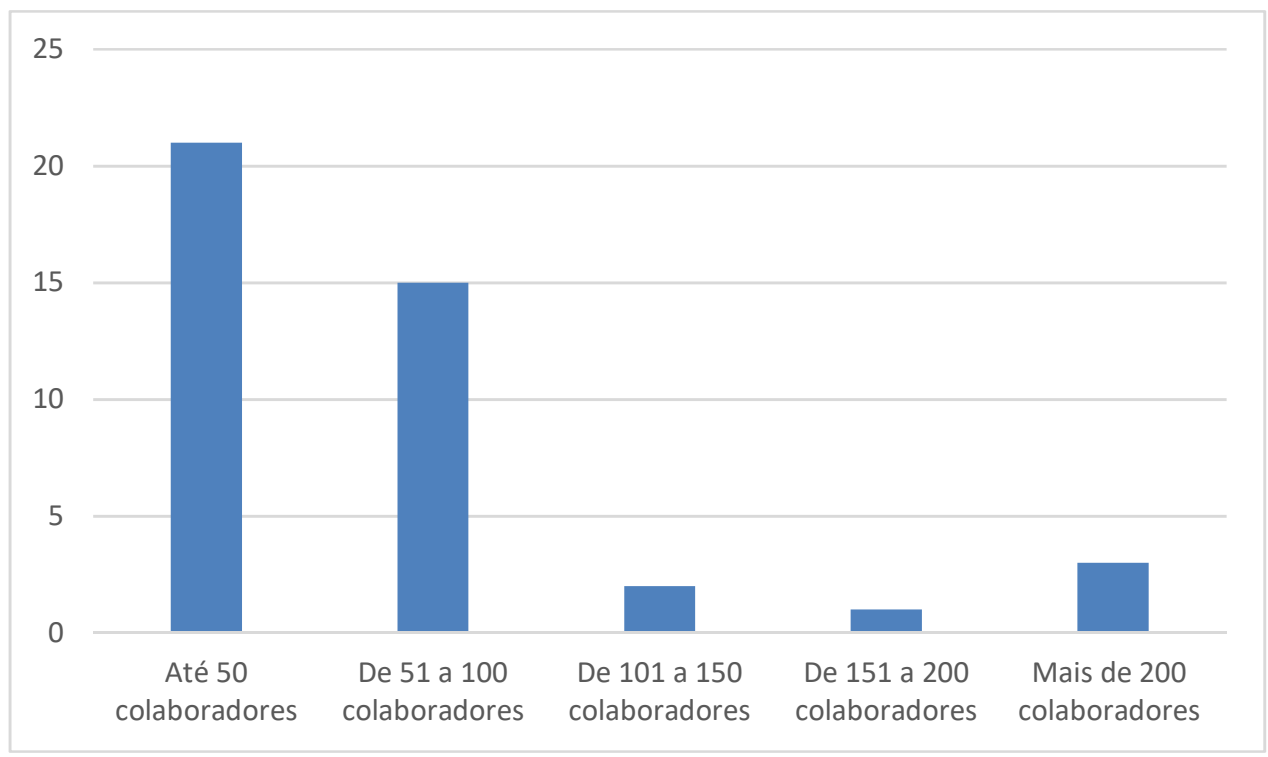

Fonte: Dados da pesquisa (2016).

Outra pergunta aberta que estava presente no questionário era em relação aos leitos que a empresa tem disponível; nessa questão foi definido uma escala que varia de 100 em 100 para melhor identificação dos dados e análise dos resultados.

Com isso, foram obtidas as respostas que são mostradas no gráfico2. 
Gráfico 2- Quantidade de leitos disponíveis com as quantidades respondidas

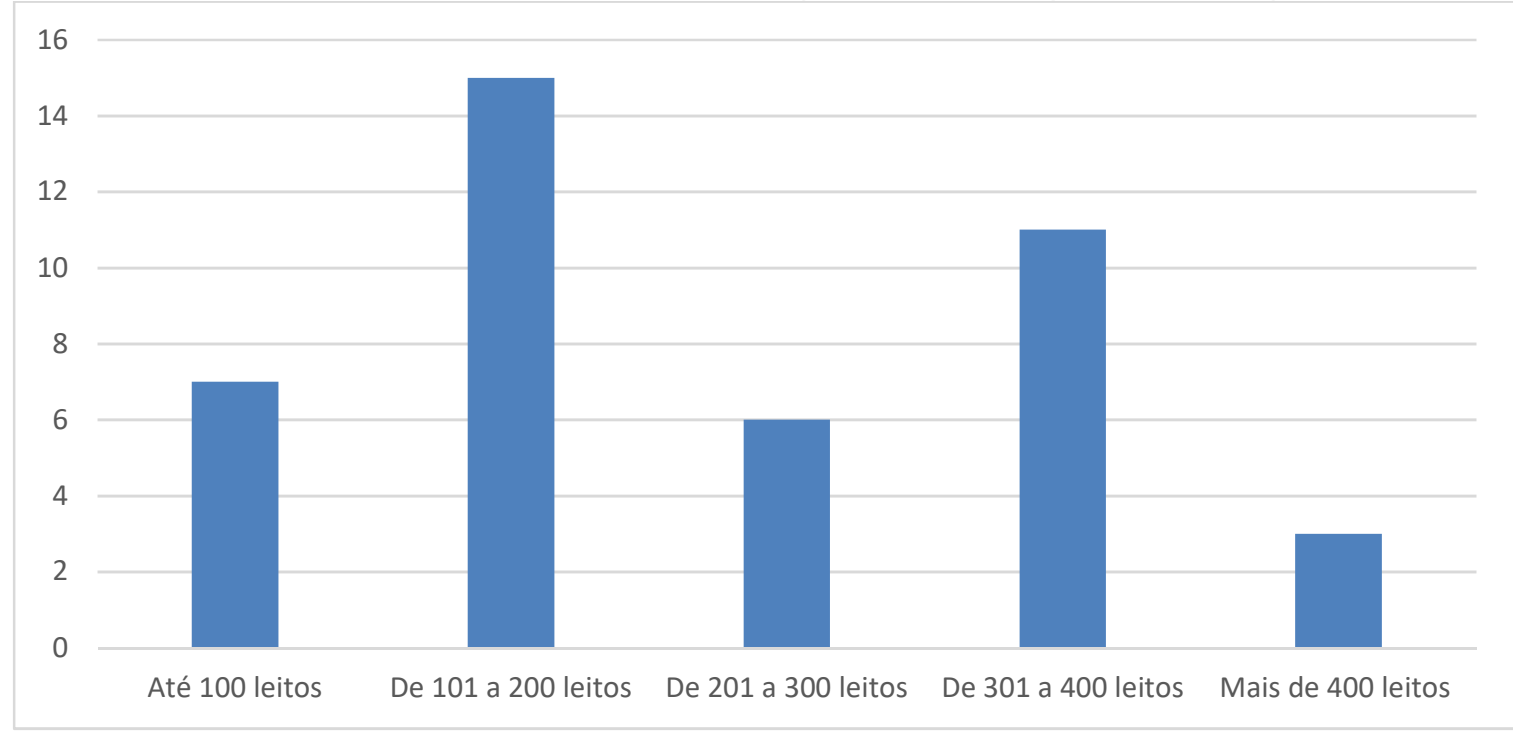

Fonte: Dados da pesquisa (2016).

A terceira e última pergunta aberta apresentada no questionário era para ser respondida pela empresa em relação a quantos anos a mesma se encontra na cidade de Foz do Iguaçu, foi definida uma variação de 10 em 10 anos para melhor compreensão dos resultados. Os resultados desse questionamento estão apresentando no gráfico 3.

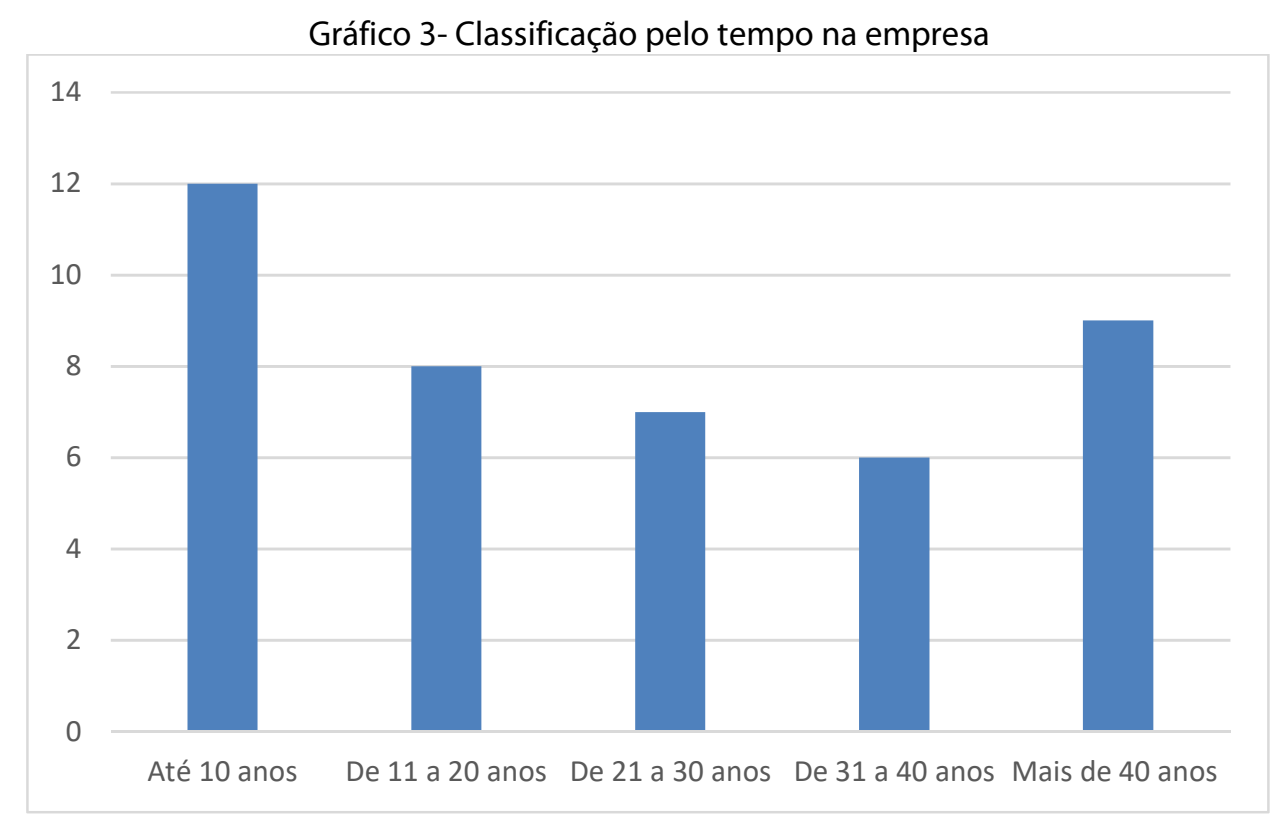

Fonte: Dados da pesquisa (2016).

O questionário, que foi aplicado nas empresas, possuía perguntas que estão relacionadas com o modelo de Walton. Esse modelo apresenta oito fatores que envolvem a Qualidade de Vida no Trabalho como pode ser observado no gráfico 4.

Quando se trata de Qualidade de Vida no Trabalho no setor hoteleiro da cidade de Foz do Iguaçu, percebeuse que no geral o assunto é trabalhado, o setor de RH dos hotéis tem a consciência que são ferramentas que ajudam a desenvolver o capital humano, porém, a prática das ações de Qualidade de Vida no Trabalho, ainda são aplicadas como um dever legal, e não como algo que acrescente à organização.

Como mostra o gráfico 4, somente algumas das ações de Qualidade de Vida no Trabalho estão sendo aplicadas pelos hotéis analisados, e outras ações como condições de segurança e saúde no trabalho, oportunidade de crescimento e segurança, trabalho e espaço total de vida e relevância social da vida no trabalho foram os que menos apresentaram como ações presentes no cotidiano desses hotéis.

O Gráfico 4 apresenta os Oito Fatores de Walton, método este utilizado na aplicação do questionário. Quando finalizada a coleta dos questionários junto aos hotéis pesquisados, foi feita a tabulação dos dados no Excel, resultando 
de modo geral, as ações que os hotéis aplicam ou não. No Gráfico 6 foi levado em conta o total geral de cada fator, para que assim pudessem ser percebidos quais dos fatores são mais utilizados pelos hotéis, e quais não são.

Na compensação Justa e Adequada, como é observado no gráfico 4, os hotéis pesquisados da cidade de Foz do Iguaçu aplicam em sua maioria esse fator na empresa, porém deve haver uma melhora pois esse fator busca a adequação das normas de compensação do serviço que o colaborador presta a empresa; tanto salarial, que trata-se de sua remuneração, se está de acordo com o piso salarial pré-estabelecido pela categoria em que ele está inserido, como também se suas horas extras estão sendo contabilizadas de forma correta. Essas ações, quando colocadas em prática, fazem com que o colaborador se sinta valorizado, diminua a procura e até mesmo a troca de emprego e tenha muito mais ânimo para execução de suas atividades, trazendo o retorno que a empresa espera.

Em condições de Segurança e Saúde no Trabalho, segundo fator citado por Walton, trata-se das condições em que o ambiente se encontra, como a ergonomia está sendo aplicada, se o clima organizacional é saudável, e se sua segurança está sendo tratada com a devida prevenção. Quando tratado de forma responsável e seguindo a legislação e normas técnicas estabelecidas pelos órgãos responsáveis, essas práticas de Segurança e Saúde no Trabalho, trazem resultados significativos para a empresa, com a diminuição de atestados médicos, afastamentos por doenças que podem ser evitadas, e até acidentes graves de trabalho, a empresa consegue manter seu quadro de colaboradores sem registros de ausência no trabalho. Há uma melhora nesse quesito, mas o número de hotéis que ainda não as praticam, ainda é alto, quase empatando os resultados entre sim e não, o que leva a questão de só ser praticado o que é obrigatório por lei, fiscalizado e normatizado.

Gráfico 4 - Oito fatores de Walton

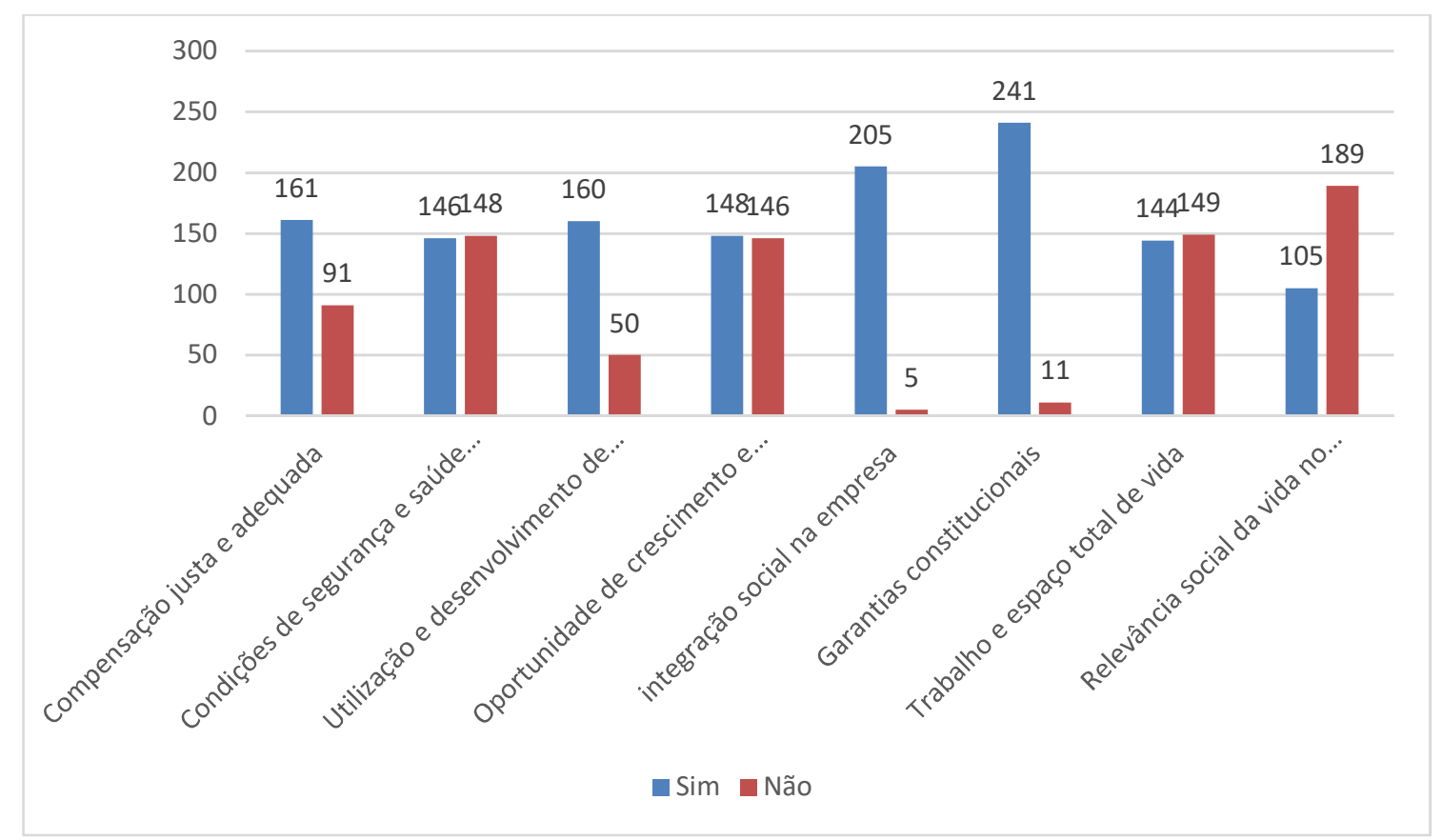

Fonte: Dados da pesquisa (2016).

No fator Desenvolvimento e Utilização das Capacidades, onde as ações buscam a quantidade e qualidade de capacitação que a empresa proporciona ao seu capital humano, o empoderamento que o colaborador tem perante suas funções e as informações que ele tem a sua disposição referente as suas atividades, funções, direitos e deveres dentro da organização. A utilização de desenvolvimento dessas habilidades e capacidades faz com que o colaborador venha somente a somar na empresa, ele trará soluções de problemáticas, que um colaborador, que não recebe tais incentivos, não tenha. Nessa pesquisa, foi constatada, que a grande maioria dos pesquisados, proporciona algum tipo de incentivo a esse fator, o que faz contribuir para o desenvolvimento do empreendimento, e do setor em toda a cidade, por terem ações de Desenvolvimento e Utilização das Capacidades presente no cotidiano desses colaboradores. Apesar de quase empate neste fator, ainda prevaleceu o não, o que mostra que quando se trata de ações de Qualidade de Vida no Trabalho, onde o colaborador tenha que se ausentar de suas atividades, ou é preciso que se faça algum tipo de investimento nessas atividades, a sua execução fica comprometida, e por muitas vezes é desaprovada, e não levada adiante.

Oportunidade de Crescimento e Segurança lida com as chances do colaborador se sobressair na empresa, quando ele tem oportunidades de crescimento, almeja cargos, percebe que seu emprego está sendo cuidado pela 
diretoria, o colaborador se sente seguro em saber que sua vida profissional e suas condições estão asseguradas, e isso somente é possível quando a empresa é bem estruturada e transparente com seus colaboradores. Nesse quesito, a pesquisa apontou que as respostas positivas e negativas se mantiveram praticamente empatadas, e quando este fator é empregado faz frente às adversidades que o mercado enfrenta.

Quando tratamos do fator de Integração Social na Empresa, é importante citar que esse fator vai além do trabalho interno e as ações de Qualidade de Vida no Trabalho que se menciona em outros fatores. Esse fator deve ser cuidadosamente administrado pela gestão de pessoas, desde o ato da contratação, nas políticas internas, e no controle de suas normas, para que o colaborador, se antes não tivesse a postura necessário, se enquadre naquilo que a empresa acredita, em um ambiente de trabalho sem quaisquer discriminações de raça, credo ou cor; igualdade no crescimento profissional e pessoal e comunicação entre gerencia e colaborador. Como mencionado na pesquisa, as ações que envolvem esse fator, são postos em prática, quase em sua totalidade de hotéis pesquisados, o que mostra que a boa convivência é preservada e a discriminação é percebida como algo que deve ser combatido.

Nas Garantias Constitucionais, leva-se em conta as leis trabalhistas, se os hotéis seguem as leis regidas, se os benefícios oferecidos estão sendo oferecidos de forma correta, de acordo com convenção do setor e se o direito à liberdade está sendo preservada, por tratar se de atos constitucionais, onde o não cumprimento pode fazer com que o hotel responda judicialmente, a maioria das ações desse fator é praticada pelos hotéis pesquisados, o que sugere a conscientização e o acesso às informações básicas de recursos humanos que esses hotéis têm acesso.

O sétimo fator estabelecido pela pesquisa foi o de Trabalho e Espaço Total de Vida, que cuida do lazer do colaborador, integrando seus familiares, tempo livre, programas em que o colaborador é sujeito à recreação de forma que faça com que ele relaxe, e consiga estar se renovando, para que execute suas funções com a devida eficiência. $E$ esse fator, não está sendo muito praticado pelos hotéis pesquisados, prevalecendo as empresas que responderam não, por isso deve haver uma melhora, pois o colaborador deve se sentir satisfeito com sua vida pessoal.

Relevância Social da Vida no Trabalho, este fator nos traz ações relacionadas com a execução de programas, onde o foco é o tratamento específico de doenças comuns. Visa a preservação do meio ambiente, também com programas para a sustentabilidade, e se o colaborador tem uma boa impressão do hotel onde trabalha. A Relevância Social da Vida no Trabalho foi o item que obteve a maior quantidade de respostas negativas, onde essas ações quase não são praticadas, sabendo que, dependendo do porte do hotel, alguns desses programas ficariam inviáveis, financeiramente. Porém, um trabalho de conscientização, para que os colaboradores consigam ter a percepção do mal que fazem se não previnem, precisa ser feito para transformar o custo em benefício eficaz.

\section{CONSIDERAÇÕES FINAIS}

Nesta pesquisa, foi analisada a Qualidade de Vida no setor hoteleiro da cidade de Foz do Iguaçu, onde inicialmente foi identificada a grande importância desse setor por se tratar de um fator determinante na economia da cidade. Como a cidade é turística, e recebe visitantes do mundo inteiro, a prestação de serviço do setor hoteleiro acaba sendo um ponto determinante para a desenvolvimento da cidade como um todo.

No setor hoteleiro da cidade de Foz do Iguaçu, existem 4 categorias de hotéis, que são divididos segundo a Prefeitura Municipal da cidade de Foz do Iguaçu (2015) em: Superior, Luxo, Turístico e Econômico, e para que o estudo fosse possível, foi delimitado que a pesquisa seria com os hotéis das categorias superior e luxo que são os que possuem diárias a partir de R\$ 161,00. Essas duas categorias somam uma totalidade de 45 hotéis, onde 42 deles responderam o questionário proposto pelas autoras onde foram levantadas as ações de Qualidade de Vida no Trabalho na cidade de Foz do Iguaçu, segundo os oito fatores de Walton.

Com as respostas que foram obtidas com a aplicação do questionário, é possível responder ao problema de pesquisa proposto por essa tese, que é identificar quais as ações de Qualidade de Vida no Trabalho são implementadas pelo setor hoteleiro nas categorias luxo e superior da cidade de Foz do Iguaçu.

Dentro dos oito fatores do modelo de Walton, foram estabelecidas algumas ações de Qualidade de Vida no Trabalho relacionada a cada fator, onde o responsável por responder o questionário assinalava com Sim ou Não para a realidade da empresa, onde os fatores que mais se destacaram foram os citados abaixo.

$\mathrm{Na}$ integração social na empresa, onde havia cinco questionamentos sobre Qualidade de Vida no Trabalho, nesse fator foi o que houve maior positividade nos resultados, pois a maioria dos hotéis aplica essas ações que são: intolerância ao preconceito, clima organizacional harmonioso, reclamações de notificações de relação entre chefia e colaborador, reclamações de notificações entre colaboradores, e igualdade de crescimento e oportunidades.

Outro fator do modelo de Walton que confirmou a aplicação dessas ações foi o de garantias constitucionais, onde havia 6 perguntas de Qualidade de Vida no Trabalho, e dessas 6 a maioria dos hotéis faz uso, sendo elas: 
informações sobre os deveres e direitos, regulamento interno formalizado, liberdade de expressão, realização de exame admissional, jornada de trabalho de acordo com a legislação e horários flexíveis.

No fator sobre trabalho e espaço total de vida, foram determinadas sete ações de Qualidade de Vida no Trabalho, onde foi constatado que os hotéis, em maioria, não aplicam tais ações desse fator, as ações citadas foram: tempo livre, comemoração em aniversário de colaboradores e palestras educativas, oportunidade de distração, cursos para filhos e chá de fraldas para colaboradores mulheres.

Por último, o fator de relevância social da vida no trabalho, no qual foram determinadas sete ações de Qualidade de Vida no Trabalho, onde foi questionado se as seguintes ações são implementadas: se a imagem da empresa é respeitada pelos colaboradores, programas sociais envolvendo colaboradores da empresa, se o hotel faz práticas sustentáveis, programa de apoio ao alcoolismo, saúde da mulher, programa de apoio a pessoas com diabetes e programa de apoio a pessoas com obesidade, onde depois de apurado, resultou que os hotéis da cidade de Foz do Iguaçu implementam de força não significativa, ficando negativo para esse fator.

Respondendo à pergunta questionada como problema de pesquisa, os hotéis da cidade de Foz do lguaçu implementam ações de Qualidade de Vida no Trabalho em sua maioria, porém há muito o que ser melhorado, ainda que existam muitas ações de Qualidade de Vida no Trabalho que já deveriam estar implementadas e não estão, a maioria deles implementa o que é obrigatório por lei, ou que não envolva investimentos altos ou interfira na rotina do colaborador, não pensando no bem-estar, nem tendo ciência de que um colaborador satisfeito em seu local de trabalho, feliz e saudável realiza seu trabalho de forma satisfatória trazendo benefícios para a empresa.

Em alguns questionários, nas perguntas fechadas, foram identificadas algumas observações justificando a não prática de determinada ação. Muitos relataram que na maioria dos casos não há interesse por parte dos próprios colaboradores em realizar as atividades, e também por outro lado a justificativa vinha por conta do investimento não ser viável para aquela ação de Qualidade de Vida no Trabalho.

E para responder essa pergunta de pesquisa foi necessário pesquisar os métodos e ações de Qualidade de Vida no Trabalho existentes na literatura do assunto, onde diante de pesquisa foi determinado que seria utilizado o modelo de Walton com os 8 fatores, pois com esse modelo houve uma melhor identificação das ações de Qualidade de Vida no Trabalho.

Outro objetivo específico que foi realizado nessa pesquisa para poder chegar ao resultado do problema foi a realização do diagnóstico do setor hoteleiro da cidade de Foz do lguaçu, onde foram citados os hotéis que estavam dentro da delimitação pesquisada, apresentando suas características como as quantidades de colaboradores de cada um, os valores das diárias, a quantidade de leitos disponíveis por cada um, e a quantidade de apartamentos que eles possuem. Também um breve histórico da empresa.

E como último objetivo específico realizado nessa pesquisa consiste na identificação das ações de Qualidade de Vida no Trabalho realizadas pelo setor hoteleiro de Foz do Iguaçu, onde foi o questionário aplicado para os responsáveis por cada hotel, e se tornou possível a realização desse questionário.

Essa pesquisa teve algumas limitações, uma delas é que muitos hotéis se sentiam com receio para responder às perguntas, por isso houve uma insistência nas respostas por parte das pesquisadoras, como também 3 deles resolveram se recusar a responder diante desse receio em ser divulgado o nome da empresa nessa pesquisa. Outra limitação é que a cidade de Foz do Iguaçu, sendo turística, tem muitas opções de hotéis, diante disso teve que ser limitado uma quantidade a ser pesquisada, não tendo uma totalidade assim nesta pesquisa. Houve também dificuldade durante a pesquisa pois requeria muito tempo para ser realizada, como não houve as respostas dos questionários por parte dos responsáveis dos hotéis via e-mail, estabeleceu-se a necessidade de ir até as empresas durante o horário de atendimento.

Essa pesquisa poderá servir como base para outras pesquisas no setor hoteleiro de Foz do lguaçu, pois como pesquisado, não foram encontradas pesquisas como esta disponíveis na cidade. O turismo pode se beneficiar dela, para obter informações úteis e assim haver uma influência para o crescimento da economia da cidade como um todo. Os hotéis são outros beneficiados com a pesquisa, pois podem utilizar como consulta para saber como os hotéis estão aplicando as ações de Qualidade de Vida no Trabalho, quais ações podem ser melhoradas por eles, para atrair os colaboradores e assim saber também quais as ações de Qualidade de Vida no Trabalho que os concorrentes também estão implantando nas empresas. 


\section{REFERÊNCIAS}

BOM SUCESSO, E. Relações interpessoais e qualidade de vida no trabalho. Rio de Janeiro: Qualitymark, 2002.

CASTELLI, G. Administração hoteleira. 9. ed. Caxias do Sul: Educs, 2003.

CHIAVENATO, I. Gestão de pessoas. 2. ed. Rio de Janeiro: Elsevier, 2004a.

CHIAVENATO, I. Recursos humanos: o capital humano das organizações. 8. ed. São Paulo: Atlas, $2004 \mathrm{~b}$.

FRANÇA, A. C. L. Práticas de Recursos Humanos - PRH: conceitos, ferramentas e procedimentos. São Paulo: Atlas, 2011.

GIL, A.C. Gestão de pessoas: enfoque nos papéis profissionais. São Paulo: Atlas, 2001.

GORZONI, P. M. Cultura organizacional e qualidade de vida no trabalho: um estudo com funcionários de um restaurante de FastFood. Dissertação (Mestrado) - Universidade de São Paulo (USP). Disponível em <http://www.erlich.com.br/espaco-do-conhecimento/qualidade-de-vida-dissertacoes-e-teses/> Acessado em: 07 set. 2015.

MALHOTRA, N. K. Introdução à pesquisa de Marketing. São Paulo: Pearson Prentice Hall, 2005.

MOTTA, V. L. B.; SOUSA, M. N. A. Qualidade de vida no trabalho: um estudo de caso com enfermeiros de um hospital privado. QUALIT@S Revista Eletrônica.v. 7, n. 1, p. 118-148, 2008. Disponível em

<http://revista.uepb.edu.br/index.php/qualitas/article/view/155/188>. Acessado em: 7 set. 2015.

PREFEITURA MUNICIPAL DE FOZ DO IGUAÇU. Portal do Turismo em Foz do Iguaçu. Disponível em: <http://www.pmfi.pr.gov.br/turismo/\%3bjsessionid\%3d5c4503823f3fa7e1 ef593c3f8a05>. Acessado em: 20 ago. 2015.

RICHARDSON, R. J. Pesquisa Social: Métodos e Técnicas. São Paulo: Atlas, 1999.

ROCHA, A.M. Qualidade de vida no trabalho (QVT): um estudo na loja arco-iris na cidade de Picos - PI. 2012. Monografia (Bacharelado em Administração) - Universidade Federal do Piauí, Teresina. Disponível em: <http://www.ufpi.br/subsiteFiles/admpicos/arquivos/files/TCC\%20ANDREIA-\%20(5)\%20(2).pdf_cd.pdf>. Acessado em: 6 set. 2015.

ROESCH, S. M. A. Projetos de estágio e de pesquisa em administração. São Paulo: Atlas, 1999

ROSA, M. A. S. Qualidade de vida no trabalho: análise do caso de trabalhadores de uma empresa do ramo de metalúrgica de Ponta Grossa - PR. 2006. Dissertação (Mestrado em Engenharia de Produção) - Programa de PósGraduação em Engenharia de Produção, Universidade Técnica Federal do Paraná, Ponta Grossa. Disponível em: <http://www.pg.utfpr.edu.br/dirppg/ppgep/dissertacoes/arquivos/32/Dissertacao.pdf>. Acesso em: 13 nov. 2015. 